\title{
Urbanizaciones cerradas en áreas inundables del municipio de Tigre: ¿producción de espacio urbano de alta calidad ambiental?***
}

\begin{abstract}
From the last decades of the twentieth century, private economic agents began building gated communities over flood-prone areas of the periphery of the Greater Buenos Aires Agglomeration, via the incorporation oflabour, major investments and specialized technology. This process of private production of urban space, which brings together public and private interests, has been legitimated through discourses relating to "sustainable development" and "environmental recovery". As a consequence, 'urban business' is generated that, in contradiction to what it claims, alters environmental functionality in an unprecedeted way. In this article, the contradictions that emerge in the processes associated with the production of 'high environmental quality' urban space is addressed. This is pursued in terms of the conflict between the discourses and practices of the social actors that intervene, based on the paradigmatic case of the gated communities of the Tigre municipality.
\end{abstract}

Key words: production of urban space, gated communities, flood-prone areas, public and private agents, ecological issues, Tigre municipality.

\section{Resumen}

Desde la última década del siglo XX, los actores económicos privados comenzaron a producir urbanizaciones cerradas sobre áreas inundables de la periferia del Aglomerado Gran Buenos Aires, a partir de la incorporación de trabajo, grandes capitales y tecnologías especializadas. Este proceso de producción privada de espacio urbano, en el que convergen intereses tanto públicos como privados, ha sido legitimado a través de discursos referidos a las nociones de "desarrollo sustentable" y "recuperación ambiental", viabilizando el avance de grandes "negocios urbanos" que, contradictoriamente a lo que se sostiene, tienden a una alteración de las funciones ambientales sin precedentes. En este trabajo se abordan las contradicciones que surgen de los procesos asociados a la producción de espacio urbano de "alta calidad ambiental" en términos de la confrontación entre los discursos y las prácticas de los actores sociales intervinientes, a partir del caso paradigmático de las urbanizaciones cerradas del municipio de Tigre.

Palabras clave: producción de espacio urbano, urbanizaciones cerradas, áreas inundables, actores públicos y privados, cuestión ecológica, municipio de Tigre. 


\section{Introducción}

A ligual que otras ciudades del mundo (Blakely y Snyder, 1997; Caldeira, 2000; Davis, 1990; Glasze, 2005), parte importante del crecimiento espacial del Aglomerado Gran Buenos Aires $(\mathrm{AGBA})^{1}$ se está realizando por medio de la construcción de urbanizaciones cerradas $(\mathrm{UC})^{2}$ en sus áreas periféricas, que constituyen negocios urbanos muy rentables.

Las UC son un fenómeno con una larga historia en la periferia de dicha aglomeración. Sus primeros antecedentes fueron los countries

* Becario doctoral CONICET- Universidad de Buenos Aires. E-mail: diegomrios@fibertel.com.ar

** Investigador CONICET- Universidad Nacional de San Martín- Universidad de Buenos Aires. E-mail: pedro. pirez@unsam.edu.ar.

*** Este trabajo se basa en avances de una investigación que desarrolla Diego Ríos, con una beca doctoral del Consejo Nacional de Investigaciones Científicas y Técnicas -CONICET-, en el marco de los siguientes proyectos de investigación de la Universidad de Buenos Aires: "Riesgo, vulnerabilidad social y catástrofes. Estudios de caso”, dirigido por la Dra. Claudia Natenzon; "La configuración urbana de la Región Metropolitana de Buenos Aires en los años '90", dirigido por el Dr. Pedro Pírez.

De acuerdo al INDEC, se denomina AGBA al área geográfica delimitada por la "envolvente de población" que comprende el límite hasta donde se extiende la continuidad de viviendas urbanas. Esta línea se mueve con el tiempo y no respeta las delimitaciones administrativas de los municipios (incluidos total o parcialmente). El AGBA abarca la Ciudad de Buenos Aires y se extiende sobre el territorio de la provincia de Buenos Aires, integrando la superficie total de 14 municipios, más la superficie parcial de otros 16 (esto sin contar una muy pequeña participación de Cañuelas y La Plata) (INDEC, 2003)

2 Asentamientos privados que se construyen fuera de la red pública de la ciudad, físicamente separados por alguna frontera material (perímetro delimitado por algún tipo de cerramiento), con producción privada de los servicios urbanos dentro de su territorio y un conjunto muy amplio de servicios (seguridad, recolección de residuos, etc.) y actividades como recreación, educación, etc. Se identifica en el mercado inmobiliario la siguiente tipología: club de campo, barrio cerrado, mega-UC o ciudades-pueblo, country náutico, clubes de chacras o estancias cerradas. Las denominaciones club de campo y barrio cerrado son las únicas definidas por la normativa vigente (decreto-ley $\mathrm{N}^{\circ}$ 8912/77 y resolución $\mathrm{N}^{\circ}$ 74/97 de la Secretaría de Tierras y Urbanismo de la provincia de Buenos Aires) (Ríos, 2005).

Recibido el 17 de julio de 2006

Aceptado el 18 de marzo de 2007
Tortugas y Highland Park, fundados en las décadas de 1930 y 1940, respectivamente. Estos countries estuvieron dirigidos a los sectores más selectos de la sociedad porteña vinculados a prácticas deportivas, tales como el polo o la hípica realizadas, por aquellos años, en ámbitos rurales. En la década de 1960 aparece el primer country náutico sobre el bajo ribereño del Río de la Plata: el Boating Club San Isidro. Dicho emprendimiento, ubicado en la localidad homónima, ofrece el concepto de la amarra privada junto a la segunda residencia, convirtiéndose en un referente de este tipo de UC. En la década de 1970 se produce la primera expansión de countries, la cual estuvo asociada al aumento de la inseguridad, al tipo de urbanización que posibilitó la reglamentación del decreto-ley provincial 8912/77 de "Ordenamiento territorial y uso del suelo" inmobiliario al incorporarse los sectores medioaltos al consumo de este tipo de productos, entre otros aspectos.

Pero es recién a mediados de la década de 1990 cuando se evidencia la más significativa expansión de UC en la periferia del AGBA, siendo esta vez los barrios cerrados de vivienda permanente dirigidos a sectores medios y medio-altos, los que participaron de manera más destacada en ese crecimiento. Según Torres (2001), para el año 1990 se contabilizaban 91 UC y para el año 2001 ya existía un total de 461 UC, localizándose el 70 por ciento de ellas en las cercanías de la autopista Acceso Norte, al noroeste de la indicada aglomeración. A comienzos de este nuevo siglo el fenómeno todavía no es muy significativo en términos de la población involucrada (cerca de 100.000 habitantes permanentes y un potencial de 500.000 , para una ciudad que supera los 12 millones de habitantes), pero sí lo es en términos de superficie ocupada: $300 \mathrm{~km}^{2}$; es decir, una vez y media la superficie de la Ciudad de Buenos Aires. Así, el crecimiento de

Las disposiciones sobre los estándares de urbanización establecidas en el decreto-ley 8912/77 cercenaron el crecimiento del mercado de los "loteos populares" que tuvo su auge entre las décadas de 1940 y 1960 en la periferia del AGBA. Así, al tiempo que disminuía la rentabilidad de las empresas loteadoras, aparecía la posibilidad de desarrollar otro producto, dentro de un marco jurídico un poco más definido, dirigido esta vez a los sectores altos y medio-altos: el country club o club de campo. 
las UC consolida y tensa las desigualdades sociales existentes, al yuxtaponer este tipo de emprendimientos y los asentamientos precarios (incluso en algunos casos villas miseria) en la periferia de dicha aglomeración (Pírez, 2004).

Esta última expansión de UC se enmarca en la modificación de la articulación público-privado ocurrida en los años noventa en Argentina, vinculada a la disminución de las inversiones públicas, al apoyo estatal a la actividad privada y al papel protagónico de las inversiones privadas en la producción del espacio urbano. Asimismo, se relaciona con un cambio de la intervención estatal, menos orientada por los "intereses generales" que por intereses económicos particulares. Estaríamos ante un caso particular de lo que en términos generales ha sido considerado el pasaje del "administrativismo" al "emprendedorismo", cuya tendencia es la conformación de coaliciones entre actores públicos y actores económicos privados para atraer mayores inversiones (Harvey, 2005). También debe destacarse la aparición de nuevos actores y la transformación de algunos existentes, en gran medida por la participación de capitales internacionales, con un peso cada vez mayor en la producción de la ciudad (Pírez, 2002).

En ese contexto, se amplían y mejoran los accesos viales (autopistas) al centro del AGBA, por medio de su concesión a empresas privadas, aumenta el parque automotriz y su participación en la distribución de los viajes, a la vez que se incorporan capitales (en algunos casos internacionales) al mercado de tierras. Como consecuencia, ciertas áreas de la periferia de dicha aglomeración se volvieron atractivas para la inversión inmobiliaria, no solo por la reducción de tiempo para su acceso, sino también por la puesta en valor de las especificidades de sus condiciones de sitio y posición.

Las tierras altas de la periferia del AGBA, muchas de ellas de gran potencialidad agrícola, fueron las más valorizadas por los actores económicos privados para la producción de UC. Sin embargo, una considerable cantidad de tierras correspondientes a áreas de máxima inundación, también empezaron a tornarse atractivas para el desarrollo de estos emprendimientos a partir de los años noventa ${ }^{4}$. No obstante, debe recordarse que la ocupación de esas áreas inundables de la periferia del AGBA tiene una larga historia. En ese proceso los sectores de menores recursos fueron los que tuvieron mayor participación, tanto a través del submercado legal de "loteos populares" como por medio de la ocupación ilegal. En estos casos la edificación de las viviendas sobre palafitos fue el sistema constructivo de mitigación más difundido a pesar de que muchos de ellos no adoptaron ninguno. Por su parte, los sectores medios y medio-altos también ocuparon algunas zonas de esas áreas inundables (por lo general las más valorizadas por sus condiciones de localización), adoptando preferentemente la edificación de sus viviendas sobre terraplenes de tierra como sistema constructivo atenuante.

No solo las condiciones de sitio y la relativa lejanía del centro de la aglomeración participaron como factores limitantes de la ocupación de las áreas de máxima inundación, sino que también fueron relevantes -en cierta medida- las restricciones legales (provinciales) para su urbanización. El primer instrumento fue el decreto No 21.891/49, que prohibió fraccionar lotes urbanos sobre zonas anegadizas, y fue derogado en 1953. La ley No 6053/54 permitió la construcción de casas sobre pilotes en zonas inundables, puesto que no existía obligación de rellenar los terrenos inundables hasta ese momento. Mediante la ley 6254/60 se prohibió realizar fraccionamientos por debajo de cota mínima de piso de 3,75 m (Instituto Geográfico Militar-IGM) (Herzer y Clichevsky, 2001). En la actualidad los proyectos de UC que quieren desarrollarse en la periferia inundable del AGBA deben cumplir con esta última ley al presentar el estudio de aptitud hídrica y el proyecto de obra hidráulica ante la Dirección de Saneamiento y Obras

\footnotetext{
$4 \quad$ Esas áreas forman parte de los valles de inundación de los ríos Luján y Reconquista, de los bajos ribereños del Río de la Plata y del Delta del Paraná, y pertenecen a los municipios de Escobar, Tigre, San Fernando, San Isidro y Berazategui. Dos son las limitaciones ambientales más importantes que presentan las áreas de máxima inundación: el alto nivel de la napa freática, que hace a esos suelos sumamente anegables, y las inundaciones recurrentes, tanto por desbordes de los ríos y arroyos que las atraviesan, como por el efecto de las "sudestadas" del Río de la Plata, que dificulta el escurrimiento de las aguas.
} 
Hidráulicas del Ministerio de Obras y Servicios Públicos de la provincia de Buenos Aires.

Ahora bien, ¿`cómo fueron superadas en el caso de las UC las limitaciones físico-naturales y jurídicas que impedían transformar las tierras inundables en tierras urbanizables, dando lugar a un formidable negocio urbano? Con la incorporación de trabajo, grandes capitales y tecnologías especializadas (movimiento de suelos y refulado hidráulico) $)^{5}$ se edificaron enormes rellenos, que implicaron el traslado de millones de metros cúbicos de suelos, permitiendo alcanzar la "cota de seguridad" requerida por las normas. De esta manera, dichos rellenos fueron el sistema constructivo utilizado para incorporar esas condiciones físico-naturales adversas al proceso de producción del espacio urbano y, al mismo tiempo, cumplir con la reglamentación vigente.

La elaboración de un andamiaje discursivo asociado a las nociones de "desarrollo urbano sustentable", "recuperación ambiental" y "valorización del paisaje" acompañó ese proceso, y en un contexto de creciente "sensibilidad ecológica", se orientó a legitimar y viabilizar el avance de esos negocios urbanos.

Ese discurso fue introducido por los empresarios inmobiliarios, justificando la producción de UC sobre rellenos como alternativa sustentable para urbanizar el suelo inundable del municipio de Tigre con productos de alta calidad ${ }^{66}$. En esos casos, calidad y relleno van juntos. Dada la envergadura de la operación para su producción y los costos a ella asociados, la rentabilidad queda condicionada a su orientación hacia el consumo de los sectores de mayores ingresos. El discurso

\footnotetext{
5 Los rellenos son uno de los sistemas constructivos que se adoptan para mitigar los efectos negativos propios de las áreas inundables y/o anegables. Dichos sistemas se construyen, principalmente, a través de dos técnicas: la de movimiento de suelos y la de refulado hidráulico. La primera consiste en la excavación y traslado de suelos para el relleno, generándose grandes pozos. La segunda consiste en endicamientos perimetrales que son rellenados a través de mangas con agua y suelos (refulado hidráulico). Una vez expulsados los líquidos, los suelos decantan y forman el relleno donde luego se construye.

6 Frente a esas proposiciones, en alguna medida subordinas a ella, se levantaron opiniones contrastantes de parte de los actores ambientalistas.
}

ambiental, y el producto urbano que justifica, resulta coincidente con la estrategia del gobierno local de garantizar cierta homogeneidad social evitando el crecimiento de los asentamientos de población de bajos recursos, para asemejarse más a los otros tres municipios que conforman la Región Metropolitana Norte ${ }^{7}$. El gobierno municipal adopta el discurso que justifica la producción de suelo con base en el relleno y su orientación hacia el mercado de altos ingresos. Al mismo tiempo, la producción de ese suelo urbano en el municipio de Tigre fue posible gracias a la contribución de su gobierno local, que aportó con cambios legales y producción de obras físicas. Resultaría de esta manera una coalición, o una convergencia de intereses, entre el gobierno municipal de Tigre y los grupos inmobiliarios en la promoción de la producción de suelo urbano en zonas inundables con base en el relleno. Es por ello que consideramos, e intentaremos mostrar, que discurso ambiental y cooperación público-privada son dos elementos que conforman el proceso que estudiamos.

Esa producción de UC sobre rellenos realizadas con base en una planificación privada del espacio, sin precedentes en la historia del AGBA, contradictoriamente a lo que se argumenta, generó importantes cambios en materia ambiental, alterando las funciones que brinda el ecosistema del humedal y potenciando/produciendo, al mismo tiempo, situaciones de riesgo de desastres por inundaciones.

En este trabajo se aborda la expansión de UC construidas sobre rellenos en áreas inundables del municipio de Tigre ubicado al noroeste del AGBA (ver Figura 1). Esa expansión ha sido sumamente significativa en términos de cantidad y magnitud de emprendimientos: entre los años 1991 y 2001, la superficie ocupada por las UC sobre rellenos en las áreas inundables del sector continental de Tigre creció cerca de 20 veces, superando las 3.300 hectáreas. Por lo demás, esas operaciones presentan enormes potencialidades para Tigre si se considera la gran disponibilidad de tierras

Se trata de una asociación de cuatro municipios metropolitanos ribereños del norte del AGBA (Vicente López, San Isidro, San Fernando y Tigre) formada para potenciar sus capacidades de gestión y la atracción de capitales. 
Figura 1. Mapa del Aglomerado Gran Buenos Aires (2001)

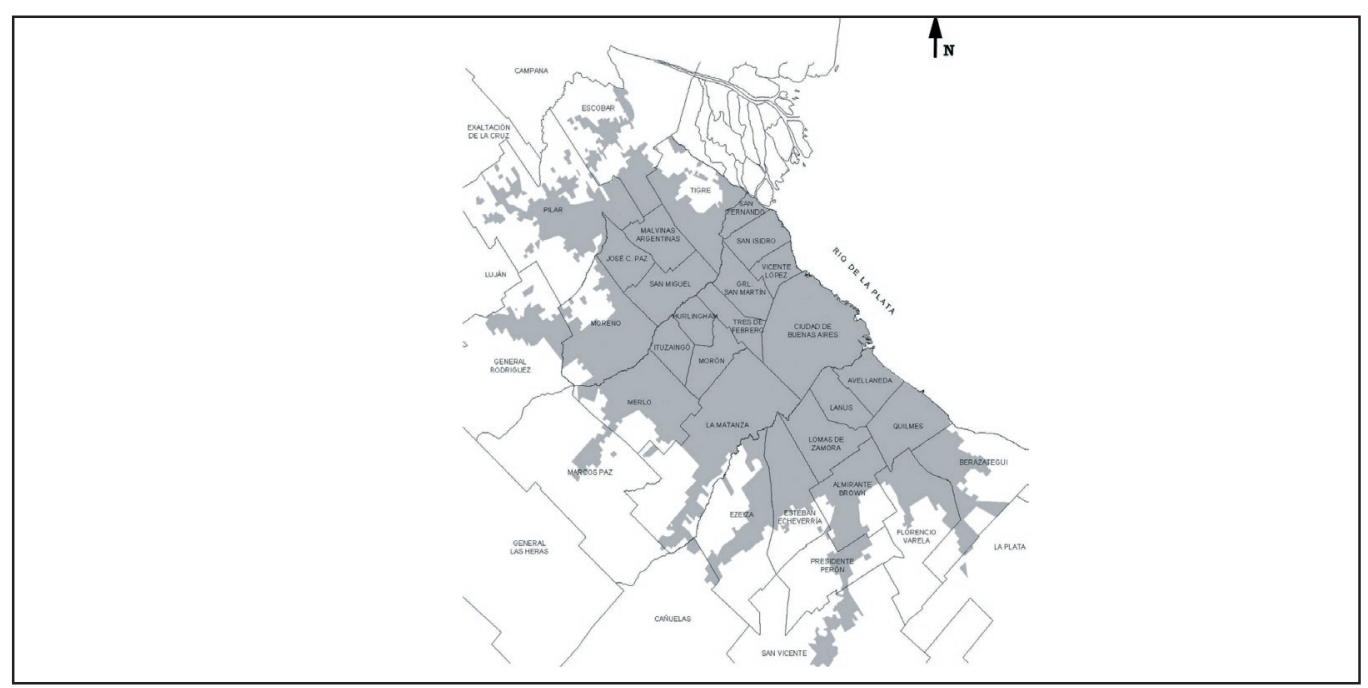

Fuente. Elaboración propia en base a INDEC (2003).

económicas localizadas en su sector de islas del Delta del Paraná (Ríos, 2002).

Más específicamente, se indagan las contradicciones que surgen en los procesos de producción privada del espacio urbano con la expansión de UC de "alta calidad ambiental" para el caso de las áreas inundables del municipio de Tigre, por medio del análisis de los discursos y de las prácticas vinculadas a dichos procesos. Se utiliza, para ello, información secundaria (documentos oficiales, bibliografía específica, revistas y periódicos, propaganda inmobiliaria, planes directores y de manejo ambiental, etc.) e información primaria recogida en trabajo de campo mediante entrevistas abiertas.

En el siguiente apartado se presenta el marco teórico-conceptual desde donde se aborda el análisis, tanto de la producción del espacio urbano como de la difusión de la "cuestión ecológica". A continuación, se caracteriza y analiza la articulación entre actores públicos y privados que posibilitó la expansión de las UC construidas sobre rellenos en áreas inundables del municipio de Tigre y sus consecuencias ambientales. Se toma como caso paradigmático la planificada mega-UC Nordelta. En el último apartado se exponen algunas consideraciones finales.

\section{Producción de espacio y cuestión ecológi- ca. El caso de las urbanizaciones cerradas de la periferia del AGBA}

La producción de espacio se ha convertido en una de las actividades más rentables, atrayendo capitales que se mueven de un sector a otro de la economía. Se asiste a una tendencia que va del espacio de consumo (particularmente productivo) al consumo del espacio. Es decir, cada vez más se compran y venden pedazos de espacio para la reproducción de la vida. Esto implica que el espacio se torna mercadería, entra en el circuito de cambio, y, por lo tanto, en la esfera de la comercialización, lo que limita su uso a las formas de apropiación privada, señalando el triunfo del valor de cambio sobre el valor de uso (Lefebvre, 1976, Lefebvre, 1995; Carlos, 2004).

La producción de espacio, en tanto relación sociedad-espacio mediada por el trabajo humano, implica fundamentalmente un proceso de valorización del mismo. Así, la apropiación de recursos del espacio, la construcción de formas humanizadas sobre él, la conservación de esos constructos, las modificaciones, sean del sustrato natural o de las obras realizadas por la sociedad, representan una creación de valor. En el proceso de valorización del espacio la renta, en tanto expresión de la propiedad privada, adquiere un papel primordial. Más aún 
cuando se convierte en renta monopólica, es decir, cuando se produce una valorización de cualidades singulares, únicas o raras (sean naturales o construidas) del espacio. Dichas cualidades por sí solas no le otorgan un valor especial a determinado espacio, es decir, no son inherentes al mismo, sino que están asociadas a la valorización que de ellas hace la sociedad (Moraes y Da Costa, 1987).

Las cualidades del espacio no son algo estático, sino componentes dinámicos modificables por la sociedad sujetos a patrones de valorización social, influidos por los niveles tecnológicos alcanzados y por los aspectos ideológico-culturales, variables en cada momento histórico (Lindón, 1989). Principalmente, la valorización del espacio pasa por las formas de pensamiento que los hombres construyen en su relación con su espacio. De allí que en ese proceso de producción, las ideas, representaciones e imágenes que introducen los grupos hegemónicos tienden a cumplir un papel privilegiado en la producción del discurso sobre el espacio, que puede incluir como en este caso cuestiones ecológicas con carga ideológica (Carlos, 1994), intentando legitimar así los procesos de valorización y transformación de determinados espacios en beneficio propio (Lefebvre, 1995).

Entre los argumentos más potentes utilizados para legitimar la expansión urbana de las últimas décadas del siglo XX, liderada por el fenómeno de las UC, sobresale la noción de "desarrollo urbano sustentable”. La utilización de esta noción está significada por la relevancia que ha adquirido la "cuestión ecológica", particularmente desde los años setenta, en el mundo y en la Argentina. Precisamente, esta cuestión surge cuando la crisis del capitalismo acentúa la presión sobre la naturaleza y el trabajo humano como fuentes de riqueza. Para los ecologistas el primero de ellos es el centro de sus preocupaciones bajo la noción de ambiente (Thomas, 1994).

Todo proceso de producción realizado por la acción humana tiende a prescindir de algunos aspectos de la naturaleza considerados inútiles para el fin buscado. Un objetivo utilitarista produce una parcialización de la naturaleza, reemplazando su multidimensionalidad por una unidimensionalidad artificial. El propio modo de producción capitalista ${ }^{8}$ lleva a sus máximas consecuencias ese proceso al consolidar la propiedad privada (Martínez-Echevarría y Ortega, 1997). La naturaleza, cada vez más fragmentada por la propiedad, y frente a un mayor grado de explotación detrás de rendimientos superiores, evidencia una proliferación de impactos negativos de gravedad. Por consiguiente, el rápido avance de la industrialización y de la urbanización desencadenó en la "crisis ecológica" actual, la cual se expresa en los procesos de contaminación, reducción de recursos naturales, deforestación, desertificación, etc., sin precedentes en la historia de la humanidad.

Ante este contexto, los bienes naturales (agua, flora, fauna, etc.), que en otros momentos históricos eran considerados "bienes libres", pasan a ser regidos por las leyes de la propiedad privada. Los bienes naturales convertidos en "nuevas rarezas" son objetos de uso corriente y la condición de ser raros les atribuye valor de cambio, pudiendo convertirse en mercaderías. En tanto nuevas rarezas representan una condición para la (re)producción del capital, luego de ingresar en el proceso de circulación de las mercaderías. Al ponerles precio a los bienes naturales se refuerza la separación entre el hombre y la naturaleza, pese a la apropiación que hace de ella con su uso. Los bienes naturales tienden así a funcionar como soportes de la producción de nuevos valores de cambio, como naturaleza mercantilizada para ser consumida (Santana, 1999).

La creciente sensibilidad ecológica, compuesta por corrientes sin fronteras precisas, se encarna en públicos, programas y prácticas extremadamente diversificadas que permiten nuevas salidas al capital con el desarrollo tecnológico y el surgimiento de nuevos mercados. La ética ecológica amplía la esfera de la mercadería, introduciendo nuevos vectores de crecimiento: las "tecnologías limpias", la "ecoingeniería", los anticontaminates, la infinidad de "productos ecológicos", etc. De allí que algunos autores hablen de una "ecología del absurdo" cuando, por ejemplo, las exigencias que deben

El utilitarismo que se identifica como criterio de parcialización de la naturaleza, también estuvo presente en la industrialización del llamado socialismo real, de allí que se produjeran efectos ambientales no muy distintos, pese a las diferencias 
cumplir las empresas contaminantes se reducen a la incorporación de tecnologías limpias, fijando un precio a la descontaminación, transformándola en rentable (Alphandéry, Bitoun y Dupont, 1992; Lipovetsky, 1996). Para alcanzar un ambiente más limpio se proponen cambios en el uso de los distintos mecanismos de producción, recurriendo a la tecnología como la salvación de los problemas ecológicos. Se cambia el eje de una posible resolución desde lo político a lo técnico. En ese contexto, los actores estatales deberían promover una demanda que fomente el perfeccionamiento de tecnologías limpias, alejándose del control de las empresas (Fernández y Gutiérrez Brito, 1997).

La conciencia ecológica comienza a invadir la vida cotidiana desde las últimas décadas del siglo $\mathrm{XX}$ y, con mayor fuerza desde los años noventa, produciendo nuevas necesidades en la sociedad de consumo. Esa conciencia induce gustos y preferencias de consumo con determinados parámetros de calidad. En la articulación entre oferta y demanda, se engendra el "consumidor ecológico", que reconoce la repercusión de sus acciones cotidianas en el ambiente, con la creencia de que sus acciones pueden contribuir a frenar el deterioro ecológico. Estos comportamientos de los consumidores permiten ampliar los mercados introduciendo cambios, a veces insignificantes, en los procesos de producción, asumiendo que determinados clientes están dispuestos a pagar más por los productos ecológicos (Fernández y Gutiérrez Brito, 1997; Santana, 1999).

Los actores económicos privados que producen espacio urbano en la periferia del AGBA ofrecen un nuevo producto de "alta calidad ambiental" para los sectores medios y medio-altos: las UC. Esta oferta se realiza a través de una mediación publicitaria ${ }^{9}$ y de estudios de marketing que, con

\footnotetext{
$9 \quad$ En los medios gráficos (y desde hace poco tiempo también electrónicos) es donde se realiza la mayor difusión publicitaria de las UC. Entre ellos se destacan los periódicos de mayor alcance en el país (La Nación y Clarín), que, desde mediados de los años noventa, editan los suplementos semanales Countries. A ello debe agregarse la publicidad de las revistas especializadas (Clubs \& Countries, Intercountries, Vida Country, Casa Country, Tigris, etc.), las exposiciones anuales que difunden estos emprendimientos (Expo-Country, Expo-Pilar, etc.) y la defensa (y también difusión) por parte de instituciones con claros intereses en las UC (Cámara
}

un reiterativo discurso ecológico, promueven la necesidad de "vivir en contacto con la naturaleza", como práctica para una "mejor calidad de vida" En esa publicidad, al tiempo que se exaltan los servicios de alta calidad, como los sistemas de seguridad, se omiten ciertos elementos no atractivos para los sectores a los que se dirige el producto, como puede ser el paisaje deteriorado y la inseguridad asociada con los vecinos asentamientos precarios y "villas miseria"11. De allí la idea de vivir en el "campo", en contacto con la "naturaleza" y las prácticas positivas asociadas, en tanto "ocultamiento" de los aspectos negativos propios a los lugares donde se implantan ${ }^{12}$.

Se instala, cada vez con mayor potencia, como sostenía Gaviria (1971) en los años setenta, la necesidad de consumo de "espacios verdes". Se despliega una carrera por una tierra promovida especulativamente, desde una suerte de "ideología de la clorofila”, gestada por actores económicos privados vinculados a los negocios urbanos, entre los que adquieren un papel fundamental las empresas de publicidad y de marketing.

Empresaria de Desarrolladores urbanos- CEDU; Federación Argentina de Clubes de Campo- FACC; Asociación de Urbanizaciones Espaciales del Sur- ARDUES, entre las más importantes).

10 A modo de ejemplo, se exponen frases asociadas a estas cuestiones tomadas de las publicidades de algunos de los folletos que promocionan las UC: "Un lugar aparte, lejos de todo lo que usted quiere alejarse. Cerca de las mejores cosas de la naturaleza"; "Dentro de este marco natural, rodeado de verde y agua, se ofrece un sistema de seguridad de última tecnología, que garantiza tranquilidad para usted y los suyos". Es interesante cómo se reproducen los contenidos de lo que Fishman (1987) llama la "utopía burguesa".

11 Las publicidades que promocionan estos emprendimientos resaltan como aspecto positivo la vecindad de otras UC en la zona: "En Villa Nueva la diferencia está marcada por: el acceso directo al río, puertos y la presencia de amplios espacios verdes y lagunas; La existencia de grandes fracciones rurales en pocas manos; La ausencia de fraccionamientos masivos o asentamientos precarios; La vecindad de los barrios de EIDICO" (Girola, 2005; tomado de revista Tigris, julio de 2004).

12 Para reforzar esta cuestión, la mayoría de los nombres con los que se han bautizado las UC aluden a algún aspecto de la naturaleza, entre los que se pueden mencionar: Laguna del Sol; Green Point Village; Los Álamos; Rincón de la Costa; Los Sauces, Barrancas del Lago, etcétera. 
Diego Ríos y Pedro Pírez

Figura 2. Imagen satelital del área de estudio, año 2005

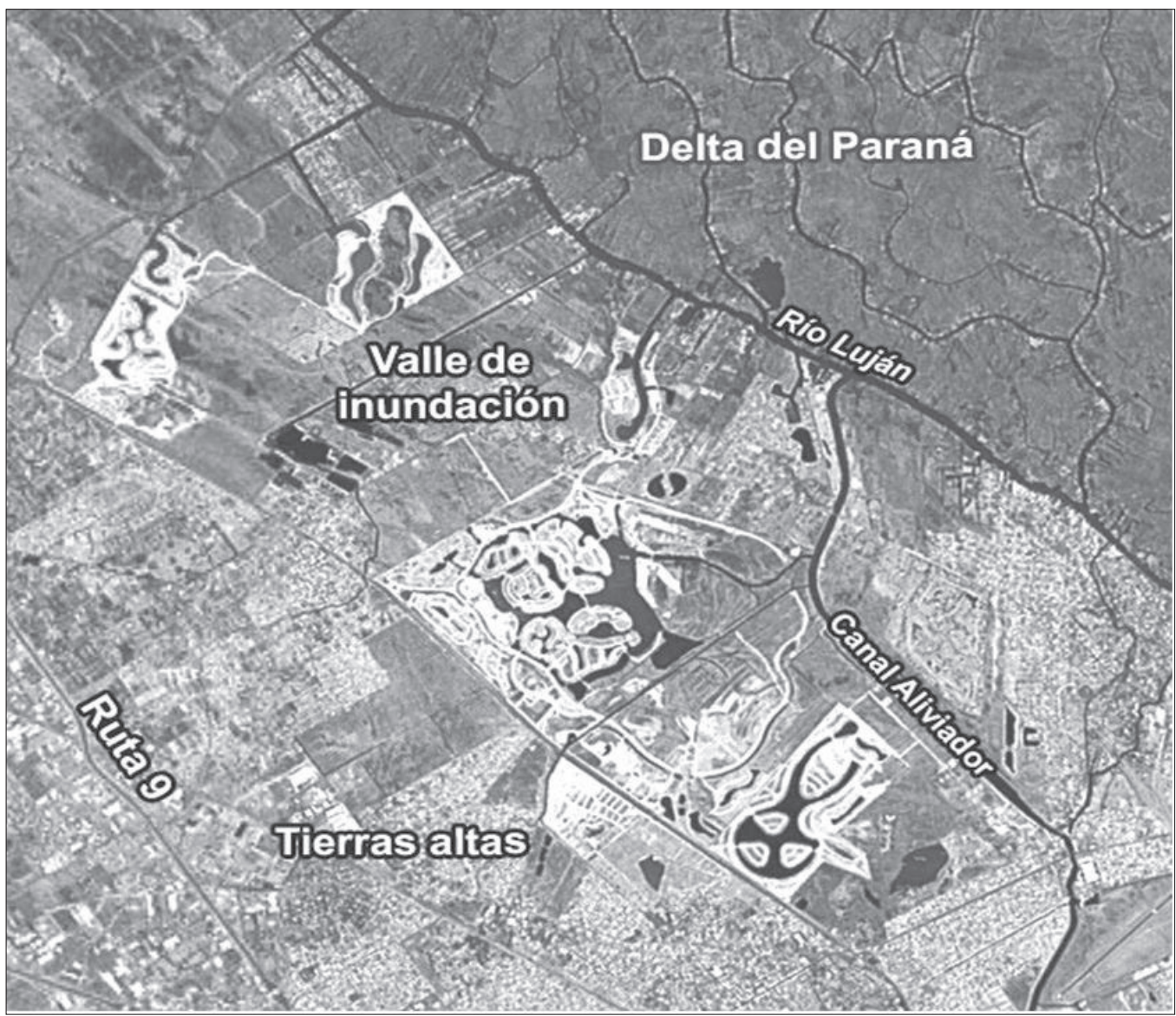

Fuente. Elaboración propia en base a Daniele, Ríos, De Paula y Frassetto (2006).

El caso del municipio de Tigre y la expansión de urbanizaciones cerradas de alta calidad ambiental.

Tigre es un municipio con una historia de más de un siglo asociada a la radicación de residencias de fin de semana, preferentemente ubicadas en su sector de islas del Delta del Paraná. Por su parte, en su sector continental, el mercado residencial dirigido a los sectores medios y medio-altos no ofrecía grandes posibilidades de expansión hasta la última década del siglo XX, pese a que cerca de un tercio de esa superficie eran tierras económicas pertenecientes a los valles de inundación de los ríos Luján y Reconquista (Núñez, Jankilevich, Brunstein y Pelfini, 1998). Las características físico-naturales (alta salinidad de los suelos, anegabilidad, inundaciones periódicas, etc.) y la incompleta accesibilidad de esas tierras restringieron el desarrollo de emprendimientos inmobiliarios para estos sectores ${ }^{13}$. Por el contrario, esas mismas características que influyeron en la formación del exiguo valor en el mercado y

13 Las excepciones a este proceso fueron: A) las 1600 hectáreas de tierras inundables adquiridas y conservadas, desde comienzos de los años '70, por las empresas Supercemento SAIC-DYOPSA sobre las que se terminaron desarrollando, a fines de los años '90, la mega-UC Nordelta, y B) el Country Boat Center, la primer UC náutica ubicada en la margen derecha del río Luján construido a fines de los años '70 en la localidad de Benavidez, y C) el Country HACOAJ (perteneciente del Club Náutico homónimo) construido en la década de 1980 sobre tierras inundables de la localidad de Rincón de Milberg. Tanto la potencial concreción de un enorme proyecto inmobiliario (Nordelta) como la construcción de los aludidos countries se constituyeron en el mascarón de proa de la expansión de las UC edificadas sobre rellenos sobre esas áreas inundables del municipio de Tigre ocurrida en la década de 1990 . 
uso productivo fueron revalorizadas por los actores económicos privados (y también públicos) a la luz del nuevo contexto socioeconómico, tecnológico y de mayores inversiones, convirtiéndose en la base fundamental para el crecimiento de las UC sobre rellenos. Esta ocupación de tierras inundables implicó cambios socioespaciales inéditos en la producción del espacio urbano residencial (ver Figura 2).

La expansión de UC en el municipio de Tigre no solo fue incentivada por las mejoras en la accesibilidad vial de la autopista Acceso Norte y por la dinamización del mercado inmobiliario, en el contexto general de mediados de los años noventa. Fue además muy importante la convergencia de intereses (económicos, políticos, ideológicos, etc.), públicos y privados, para transformar una gran cantidad de tierras consideradas "improductivas" o "baldías" en un formidable negocio urbano. Tal convergencia se hizo evidente en los discursos como en las prácticas desarrolladas por los actores públicos y privados participantes ${ }^{14}$, que tendieron hacia una puesta en valor de esas áreas inundables del territorio de Tigre.

En el plano de los discursos, los actores públicos y los actores económicos privados promovieron la realización de UC sobre rellenos y de obras conexas que, en tanto "desarrollos sustentables", permitirían una "recuperación ambiental" de esas áreas inundables. Instalaron la necesidad de realizar inversiones (públicas y, sobre todo, privadas) como promoción del "bien común", de la oferta de trabajo, del beneficio para el "conjunto" de la población local, etc. Esos discursos, en una aparente coherencia racional y objetiva, justificada por la generación de un "efecto derrame" de las UC, tendieron a legitimar los planes directores (o master plans) de esos emprendimientos y las evaluaciones de impacto ambiental (con sus correspondientes declaraciones otorgadas por el Estado), oscureciendo las contradicciones y los conflictos sociales que

14 Los actores públicos que participan de estos procesos pertenecen a diversas instituciones gubernamentales y niveles de gestión, siendo los del nivel municipal uno de los de mayor intervención en este campo. Por su parte, entre los actores económicos privados, sobresalen las empresas constructoras-desarrolladoras, inmobiliarias, consultoras, financistas, publicitarias y de marketing, entre otras, tanto de capitales nacionales como internacionales. se derivan del complejo proceso de producción de ese espacio.

Entre las prácticas llevadas a cabo por los actores públicos y privados que permitieron la puesta en valor de algunas de las condiciones de sitio y posición, se destacan la realización de obras de infraestructura (transporte, saneamiento y control de inundaciones, turístico-recreativa) y los cambios en las normativas sobre el código de zonificación del uso del suelo. Aquí el Estado adquirió un papel dinámico en la intervención de la producción de ese espacio, evidente, por ejemplo, en expresiones realizadas por el propio intendente de Tigre: "habíamos hecho mucha inversión pública para atraer la gente a Tigre, mucho dinero en mejorar la imagen para que los emprendedores pudieran tener una mejor comercialización de los barrios [UC]. Es más fácil atraer a la gente asî" (Lanusse, 2005, p. 1).

Además de las obras de ampliación y modernización de infraestructura vial de la autopista Acceso Norte, que incluye el ramal Tigre, efectuadas a mediados de los noventa, se continúan construyendo desde los primeros años del presente siglo accesos viales directos a las áreas donde se localizan las UC sobre rellenos. Entre estas se destacan:

- El corredor vial Bancalari-Benavídez, que conecta esas localidades con el Acceso Norte, obra que fue financiada por un consorcio formado por la municipalidad de Tigre y empresas constructoras-desarrolladoras de una serie de UC beneficiadas por la obra ${ }^{15}$, y

- El camino Interisleño que comunica el ramal Tigre del Acceso Norte con la ruta provincial $\mathrm{N}^{\circ} 27$, paralelo al canal aliviador del río Reconquista, realizado por un convenio entre la Subsecretaría de Obras Públicas de

15 Resolución municipal No 1401/99, Dirección de Despacho General y Digesto, Secretaría de Gobierno, Municipalidad de Tigre. En dicha resolución se registra el acta de acuerdo entre municipalidad de Tigre y las empresas Nordelta S.A., San Isidro Agropecuaria S.A., Talar del Lago S.A., Laguna del Sol S.A. y EIDICO S.A., para la conformación de un consorcio para la construcción del corredor vial BancalariBenavídez. 
la Nación (ente financiador) y la Dirección Nacional de Vialidad (ente supervisor). Hasta el momento esta obra constituye el tramo I del mencionado camino, que a través de un puente sobre el río Luján llegaría hasta el río Paraná de las Palmas en las islas del Delta ${ }^{16}$.

En los primeros folletos que promocionan las UC de Tigre ya figuraba el camino Interisleño como una obra a realizarse, mostrando a partir de ésta el interés de las empresas desarrolladoras en expandir el negocio urbano sobre las islas del Delta. Desde el gobierno municipal se afirma que esta obra va a favorecer a los productores de la zona, a pesar de que son escasas las actividades productivas que han quedado en ese sector del Delta. De avanzar en la concreción del camino Interisleño es probable que se origine un crecimiento significativo de las UC sobre rellenos en las islas, donde ya están funcionando tres emprendimientos. Además, ya ha sido aprobado por dicha municipalidad el controversial proyecto Delta del Plata, una UC de alrededor de 600 ha. que requiere realizar un puente desde el vecino sector continental de San Fernando (Videla, 2002). La posibilidad de avance de los accesos viales y de las UC a las islas del Delta genera resistencias de los vecinos isleños que no quieren ver alteradas sus prácticas cotidianas asociadas a una vida en contacto con una naturaleza menos intervenida por la sociedad.

La consolidación de las UC en un área de escasa infraestructura vial haría lógico y necesario ampliar y mejorar los accesos viales, en particular porque cada nueva familia que se radica en las UC de la zona agrega, por lo menos, dos vehículos particulares al parque automotor del municipio de Tigre.

Estos nuevos accesos viales no solo mejoran las condiciones del tránsito, sino que también (como si los nuevos caminos fuesen un by-pass) evitan a los residentes de las UC transitar por zonas consideradas "peligrosas", al estar pobladas en sus alrededores por sectores medio-bajos y bajos. En este sentido, el propio Intendente expresa las ventajas que ofrece el municipio de Tigre en relación

16 Ordenanza municipal No 2499/03, Dirección de Despacho General y Digesto, Secretaría de Gobierno, Municipalidad de Tigre. a otros donde también se han expandido las UC, pero sin que se hayan realizado obras viales que los conectan directamente con el Acceso Norte: “... los barrios nuestros [entiéndase UC] tienen un acceso limpio, franco e iluminado" (Lanusse, 2005, p. 2). Expresiones como esta, que denotan una ausencia de contacto, de encuentro, de conflicto entre poblaciones socioeconómicamente distantes, tienden a posicionar a Tigre en una situación diferencial, cada vez más importante para los compradores de UC en su búsqueda de una "seguridad idealizada", que depende también de las características de sus accesos viales.

Las licitaciones de esas obras viales han sido ganadas y llevadas a cabo (algunas actualmente en construcción) por empresas que forman parte de los dos mayores constructores-desarrolladores de UC edificadas sobre rellenos del municipio de Tigre: Supercemento SAIC.-DYOPSA, para el caso de Nordelta SA., y Pentamar SA., para el grupo Pentamar-EIDICO, ambas con experiencia en construcción en general y en obras hidráulicas y de dragado en particular. Esas obras, financiadas total o parcialmente por organismos internacionales de crédito, también implican un mayor endeudamiento del Estado para facilitar la maximización de beneficios privados (Ríos, 2002).

Entre las obras de infraestructura de saneamiento y de control de inundaciones se destacan las realizadas sobre el río Reconquista, que finaliza su curso en el territorio del municipio de Tigre, abriéndose en dos brazos: el Reconquista Chico y el Tigre, que da nombre al municipio. El río Reconquista es el segundo en importancia que atraviesa el AGBA y es uno de los más contaminados del país. Aporta un tercio de la contaminación del Río de la Plata, luego de colectar, a lo largo de sus $50 \mathrm{Km}$, los efluentes industriales y cloacales vertidos por más de 12.000 industrias y 3 millones de habitantes. Las obras están siendo encaminadas por la Unidad de Coordinación del Proyecto río Reconquista (UNIREC), ente autártico de la Dirección de Saneamiento y Obras Hidráulicas del Ministerio de Obras y Servicios Públicos de la provincia de Buenos Aires. Se financian con un crédito que tomó la provincia de Buenos Aires del Banco Interamericano de Desarrollo- BID y del Japan Bank for International Cooperation de 355 
millones de dólares. Desde la devaluación del año 2001 las obras están paradas porque se licuaron los fondos con que se contaba, sumadas a acusaciones de corrupción. De allí que todavía no se han podido finalizar etapas de obra anteriores, como la instalación de plantas de tratamiento cloacales, fundamentales para los fines de descontaminación (Ríos, 2002).

La presente situación del río Reconquista está aún lejos del objetivo de saneamiento del proyecto del UNIREC. Entre los principales impactos ambientales negativos generados durante y después de la gestión de las obras pueden señalarse:

- El desvío del caudal del río Reconquista por el canal aliviador. Dicho canal fue construido a comienzos de 1970 para aliviar los aumentos del volumen causados por precipitaciones en la cuenca. En esta oportunidad se efectuó un corte transitorio del río Tigre (que hasta el momento parece ser permanente), con lo que se desvió por el citado canal no solo la totalidad del caudal sino también la contaminación que éste transporta, afectando a otros sectores de las islas del Delta en donde residen pobladores que todavía utilizan el agua del río para aseo, consumo diario, etc. ${ }^{17}$;

- El traslado de lodos contaminados con plomo, cadmio, cromo, etc. provenientes del dragado del lecho del río Reconquista Chico, depositados en un sector de islas del Delta del municipio de Campana; y

- La disposición de lodos contaminados en los predios de la mega-UC Nordelta. La empresa licitataria del dragado y refulado del canal aliviador, constructora de la aludida UC, utilizó esos lodos contaminados como material de para la construcción de los rellenos de ese emprendimiento ${ }^{18}$.

\footnotetext{
17 Esto implicó un cambio para estos sectores en la forma en que obtienen y tratan el agua para consumo, que se expresa en mayores costos y mayor tiempo dedicado a la recolección y tratamiento del agua (Suárez y Lombardo, 2004).

18 Estas acciones fueron denunciadas por ONGs ambientalistas de la zona (Aprodelta y ProTigre) ante la Dirección de Ecología y Recursos Naturales de la Secretaría de Política Ambiental de la provincia de Buenos Aires, la que luego de pericias, comprobó la presencia de materiales conta-
}

Tal como afirman las ONG ambientalistas y los vecinos de las islas, la operación de desviar el mal olor y la contaminación que ahuyentaba a los turistas e inversores vinculados a los negocios turístico-recreativos e inmobiliarios, terminó perjudicando a otros pobladores (como los isleños) y valorizando las tierras cercanas a las márgenes del río Tigre.

El municipio de Tigre está consolidándose como uno de los principales destinos turísticos de la periferia del AGBA, sumando atractivos en el continente además de los atractivos "naturales" propios de las islas de Delta. Para fines de los años noventa se remodelaron la estación fluvial y la estación ferroviaria, y el capital privado construyó el Parque de la Costa (centro de diversiones cuyo proyecto incluyó al Tren de la Costa) y un casino. Simultáneamente, en la margen derecha del citado río, comenzaron a desarrollarse grandes edificios torre cercanos al sector turístico del centro de Tigre, alguno de los cuales ya están habitados.

Los cambios en las normativas que reglamentan la producción del espacio urbano, por su parte, fueron otra de las condiciones decisivas para promover mayores inversiones privadas en Tigre. Así, ante el contexto de los años noventa de crecimiento y presentación de proyectos de inversión en UC, el Consejo Deliberante del municipio de Tigre sancionó la ordenanza $N^{\circ}$ 1894/96 (dentro del marco regulatorio del decreto-ley 8912/77), con la que se modificó el antiguo código de zonificación de uso del suelo. Para el secretario de gobierno municipal esto garantiza: "a la gente que quería llevar adelante desarrollos urbanísticos la seguridad jurídica necesaria para que, cumpliendo con el código de zonificación, pueda encarar este tipo de emprendimientos. Esto nos permitió tener hoy un [municipio] con un crecimiento ordenado" (Sánchez, 2000, p. 2). Con la sanción de esa ordenanza, que establece una reclasificación de los usos del suelo, se regularizaron algunas de las UC que ya estaban en construcción y que se encontraban en

minantes y elaboró las actas de infracción entre los años 1999 y 2000. También fueron realizadas las denuncias ante la Justicia y el Defensor del Pueblo de la Nación. Hasta el momento no se tiene conocimiento de que estas instituciones se hayan expedido sobre estos temas. 
usos no permitidos ${ }^{19}$. El propio intendente señala a esos cambios en la normativa como uno de los factores claves del éxito de la expansión de UC en Tigre: “... el gran resultado ha sido causado por dos factores: la seriedad de los inversores y la seriedad de nuestras normas, nunca las cambiamos en el medio del juego, y si lo hacemos, lo hacemos para todos igual, porque nunca aceptamos nada por vías de excepción" (Lanusse, 2005, p. 4).

El intendente de Tigre destaca entre los mayores logros de su gestión haber allanado el camino para la radicación de inversiones privadas en UC, sin esconder sus intereses más profundos, que terminan siendo convergentes con los de los actores económicos privados (Lanusse, 2005): "hemos abierto la inversión para cambiar el sistema que existía. Porque si no hubiéramos tomado la determinación de facilitar la inversión de los barrios [léase UC] y los emprendimientos particulares; y con tantas superficies desocupadas, Tigre podría haber sido una desgracia, una gran villa de emergencia como Moreno" (p. 1) ${ }^{20}$.

Estas declaraciones muestran algunas cuestiones claves. Por un lado, el propósito de favorecer a los actores económicos privados no se limita solamente al objetivo de acrecentar los ingresos municipales a través del pago de la tasa del servicio municipal de Alumbrado, Barrido y Limpieza-ABL y, principalmente, del permiso de construcción de viviendas, sino que también se busca un cambio en el perfil socio-económico de la población, acercándose así a las características de los municipios vecinos de la zona norte del AGBA, donde predominan los sectores medios y

19 A modo de ejemplo, este podría ser el caso de uno de los grandes grupos empresarios desarrolladores de UC en el territorio de Tigre que había comprado, antes de haber sido sancionada la nueva ordenanza, parte importante de los predios perteneciente a Radio Nacional con el objetivo de realizar una UC en terrenos que se encontraban bajo la clasificación de uso "específico", el cual no autoriza el uso urbano residencial (Ríos, 2002).

20 Moreno es uno de los municipios más pobres del AGBA. Según el Censo Nacional de Población, Hogares y Vivienda de 2001 (INDEC), el porcentaje de la población con Necesidades Básicas Insatisfechas (NBI) de este municipio alcanzaba el $26 \%$, superando por más de diez puntos al promedio de los 24 municipios de la provincia de Buenos Aires que forman parte del Área Metropolitana Buenos Aires. altos. Correlativamente, se pretende evitar el crecimiento de asentamientos y "villas miseria", que en vez de generar aportes a las arcas municipales demandarían mayor gasto social solventado por el Estado. Por otro lado, en línea con los objetivos de la propuesta de conformación de una Región Metropolitana Norte, más cercanos al "emprendedorismo" urbano para atraer inversiones privadas que a la ejecución de políticas sociales, Tigre se colocaría, a partir de las millonarias inversiones en UC y otros negocios urbanos, como un nuevo nodo de atracción de inversiones privadas ${ }^{21}$.

Por su parte, el mayor protagonismo de los actores económicos privados en la transformación del área inundable estuvo asociado con la construcción de las UC sobre rellenos de refulado hidráulico, que implicó el movimiento de millones $\mathrm{de}^{3}$ de suelos para alcanzar la cota de seguridad requerida. Ahora bien, cabría preguntarse ¿de dónde y cómo se obtuvieron los suelos para construir los rellenos de las UC? Para ello se elaboraron distintas estrategias:

- La forma predominante fue (y continúa siendo) la realización de profundas excavaciones en el predio donde se desarrolla la UC. Así, se obtuvieron suelos suficientes para elevar las áreas destinadas a viviendas y servicios y se generaron enormes "lagos", que en algunos casos alcanzaron cientos de hectáreas. Dado que los lotes linderos a los lagos son los más requeridos, se optó por aumentar el perímetro de sus costas para alcanzar la mayor cantidad de lotes frentistas, con lo que esos lagos comenzaron a adquirir formas más complejas;

- A partir de excavaciones en predios cercanos, lo que produjo un paisaje de cavas abandonadas en los alrededores de las $U^{22}$. Esta

${ }^{21}$ Cabe resaltar que dichas inversiones privadas se producen en un marco de grandes carencias y prioridades sociales del municipio. Según el Censo Nacional de Población, Hogares y Vivienda de 2001 (INDEC), el municipio de Tigre alcanzaba los siguiente valores expresados en porcentaje de población: $20,3 \%$ con NBI; $54,8 \%$ sin cobertura por obra social y/o plan de salud privado o mutual; $28,1 \%$ en vivienda deficitaria; $86,2 \%$ sin desagüe en red (cloacas); $35,9 \% \sin$ agua en red; $30,2 \%$ sin gas en red, entre otros.

22 Algunas de estas cavas terminaron formando profundas "piscinas" en las que reiteradamente los bomberos voluntarios de la zona deben sacar el cuerpo de algún niño 
Urbanizaciones cerradas en áreas inundables del municipio de Tigre: ¿producción de espacio urbano de alta calidad ambiental?

estrategia fue realizada por las primeras UC que se construyeron en la zona. Asimismo, en algunos casos se compraron terrenos con cavas que, una vez readaptadas, terminaron convirtiéndose en los lagos ofrecidos por las $\mathrm{UC} ; \mathrm{y}$

- A partir de la extracción de suelos de las cercanas islas del Delta. Estos suelos fueron dragados y llevados a través de una manga, por debajo del río Luján, hacia el predio de una UC en el continente, donde fueron depositados (a partir de la técnica del refulado) en diques perimetrales de contención que, una vez decantados, formaron los rellenos ${ }^{2323}$.

La magnitud de los impactos en el sector inundable del municipio de Tigre sirvió como disparador para que los actores económicos privados elaborasen discursos orientados a justificar ambientalmente (a partir de las ideas de "saneamiento ambiental", de "valorización del paisaje", etc.) las significativas transformaciones que iban a resultarse de la construcción de las UC edificadas sobre rellenos. Para estos actores los humedales de Tigre eran considerados como "pantanos improductivos", que debían convertirse, a través de la incorporación de capitales y tecnologías especializadas, en espacios urbanos de "alta calidad ambiental" que distinguirían al "nuevo Tigre". Estos argumentos han quedado expresados en sus propias declaraciones (Fernández, 2002): “Acá había grandes espacios de tierra libre, donde no se podía vivir. Eran tierras bajas, y a través de un trabajo de ingeniería se pudo reciclar [...]. Se convierte un pantano, a través de relleno y refulado, en un lugar con lagos". A lo que agrega: "El proyecto ofrece una ciudad con mejores condiciones sociales

$\overline{\text { ahogado perteneciente a los sectores más humildes de los al- }}$ rededores (Ríos, 2002).

23 Las distintas estrategias para la obtención de suelos ocasionaron diversos impactos negativos tanto durante como después de las obras, entre los que se destacan: la rotura de la mencionada manga generó lodo en suspensión y, consecuentemente, la muerte de peces por anaerobia y diversas dificultades para el uso del agua del río por parte de la población isleña cercana; el desmoronamiento durante una fuerte precipitación de uno de los dique de contención donde se asentaban los lodos refulados, terminó afectando terrenos de uso productivo y un asentamiento de población de bajos recursos linderos, etc. (Ríos, 2002). y urbanísticas, comenzando por la recuperación de un área baja y ecológicamente deteriorada, por medio de obras de saneamiento hidráulico y valorización del paisaje, sin las cuales el terreno seguirá siendo un enorme baldío inaprovechable y peligroso". (p. 57).

Del total de la superficie transformada por las UC edificadas sobre rellenos en tierras inundables del sector continental de Tigre (alrededor de 3.300 ha. para el año 2001), más del 70 por ciento corresponde a dos mega-UC ${ }^{2424}$ : Nordelta y Villa Nueva. Ambos emprendimientos se presentan como proyectos urbanísticos planificados y en el caso de Nordelta como nueva "ciudad ambiental" ${ }^{2525}$. Es por ello que a continuación se aborda brevemente la historia de este emprendimiento y los discursos que lo legitiman como ciudad ambiental.

\section{La planificación urbana privada: el caso de Nordelta. ¿Ciudad ambiental?}

Nordelta es la mayor de las "ciudades privadas" en Argentina. Con una superficie total de 1.600 ha. está integrada por 20 barrios cerrados, con capacidad proyectada de 140.000 habitantes en 20 años, servicios de ciudades intermedias como centros de compra (shopping center y supermercado), sanatorios privados, centros de educación que incluyen desde el jardín de infantes hasta nivel universitario, accesibilidad brindada por nuevas o modernizadas autopistas y rutas, canales de navegación con acceso al río Luján, dos futuras estaciones ferroviarias, entre otros. Sus constructores-desarrolladores están llevando a cabo una inversión directa de alrededor de 250 millones de dólares que, con inversiones en comercios,

24 En términos generales, a diferencia de las otras UC, las mega-UC incluyen en su territorio equipamientos de orden superior, tales como colegios y universidades privadas, medicina privada, centros comerciales, etc.; cuentan con accesos con vigilancia privada tanto en sus límites perimetrales como en los barrios cerrados contenidos en su interior; ocupan superficies superiores a las 300 ha., poseen una población de varios miles de habitantes y una mayor participación de grupos de inversión en bienes raíces de origen internacional (Vidal Koppmann, 2002).

25 La mega-UC Puerto Palmas, localizada en el valle de inundación de los ríos Luján y Paraná de las Palmas, sobre predios rellenados linderos a la Reserva Natural Otamendi en el municipio de Campana, es difundida por los medios gráficos y electrónicos como "pueblo ecológico". 
servicios educativos, medicinales y construcciones particulares, alcanzará un total cercano a los 750 millones de dólares. Se supera cualquier inversión en proyectos urbanísticos privados de este tipo conocidos hasta el momento (Janoschka, 2002).

Nordelta comenzó como proyecto en 1972, cuando las empresas Supercemento SAIC.DYOPSA adquirieron a muy bajo costo parte importante de las tierras pertenecientes al valle de inundación del río Luján, entre las localidades de General Pacheco y Benavídez en el municipio de Tigre. Esas empresas pidieron estudios para desarrollar una nueva ciudad que descentralizara al AGBA bajo un proyecto privado, independiente de las políticas estatales. Se anticiparon a lo que sucedería dos décadas después luego de la reforma del Estado y el nuevo papel estatal en la producción urbana. Tal como sostiene el presidente de las empresas antes aludidas, el proyecto Nordelta resignificó la producción del espacio urbano, puesto que hasta ese momento el único que podía producir grandes fragmentos urbanos era el Estado y, en el caso del sector privado, la producción -en ausencia de políticas urbanísticas- se realizaba de manera sumamente especulativa, proporcionando como resultado los desprovistos "loteos populares" que predominan en el paisaje de la periferia de la aglomeración (Astolfoni y Constantini, 1999).

Esas empresas se contactan a fines de los años ochenta con el Centro de Estudios y Proyectos del Ambiente (CEPA) de la ciudad de La Plata, que ya tenía una importante trayectoria en la intervención de proyectos urbanos, para que elaborase la propuesta del plan director de Nordelta entre los años 1989 y $1999^{26}$.

26 El CEPA participó en la década de 1980 en el "Proyecto '90" encarado por la Comisión Nacional del Área Metropolitana de Buenos Aires (CONAMBA), en el que se propiciaba una descentralización institucional, administrativa, funcional y de la ocupación del suelo del Área Metropolitana de Buenos Aires. A pesar de las habituales dificultades de discontinuidad política que imposibilitaron la aplicación de estas estrategias, apareció el impulso del capital privado, que coincidió con estos criterios y les encargó el diseño de una "ciudad nueva" (Nordelta) en un lugar muy cercano a las propuestas de descentralización realizadas por el CEPA (Pesci, 2003).
En 1996, luego de haber alcanzado la seguridad jurídica unos años antes ${ }^{27}$, las empresas Supercemento SAIC.-DYOPSA comenzaron la construcción. Sin embargo, por aquellos años esas empresas entran en una etapa de fragilidad financiera, por lo que debieron buscar otros capitales para continuar el proyecto. A partir de 1998, Consultatio Inversora $S A$ se incorpora al proyecto Nordelta con la compra del 50 por ciento del paquete accionario e inversiones que provienen de capitales suizos (Astolfoni y Constantini, 1999).

La propuesta inicial del plan director de Nordelta, realizada por el CEPA a fines de los años ochenta, consistía en una ciudad abierta, incluida a la trama urbana adyacente, con una amplia heterogeneidad social (desde sectores altos hasta medio-bajos), con topes de densidades y criterios de manejo del suelo y el ambiente, y con elasticidad para su desarrollo en etapas de acuerdo con los cambios requeridos por la demanda a través del tiempo. En esa propuesta inicial las formas predominantes que adoptaba el espacio urbano se acercaban a las de la ciudad tradicional: trazado en damero, calles rectas, existencia de veredas, zonas de centralidad y urbanidad. Además se destacaba la presencia de un enorme lago central que se conectaba con el canal mayor (y su acceso al río Luján) y el canal aliviador del río Reconquista, posibilitando la circulación y renovación del agua. Alrededor de ese lago se desarrollaba una gran área verde de acceso público y por detrás de esta una avenida de circunvalación (ver Figura 3).

A fines de la década de 1990 se reorienta el proyecto inicial. El nuevo plan director de Nordelta encarna a una "ciudad de barrios cerrados" con acceso público a la oferta de servicios localizados en los bordes del emprendimiento (centro de compras, de salud, educativos, etc.). Entre los cambios que adopta el espacio urbano del nuevo

27 En julio de 1992, en un contexto políticas pro intereses privados, el gobierno de la provincia de Buenos Aires aprueba el proyecto y su plan director al sancionar el decreto $\mathrm{N}^{\circ} 1736 / 92$, bajo la figura de "nuevo núcleo urbano" (según el decreto-ley $\mathrm{N}^{\circ}$ 8912/77). Un mes más tarde el municipio de Tigre sanciona la ordenanza $\mathrm{N}^{\circ} 1297 / 92$, aprobando bajo la misma figura dicho proyecto urbanístico e incorporándolo unos años después en la reclasificación que hizo con el nuevo código de zonificación de uso del suelo municipal con la ordenanza $\mathrm{N}^{\circ} 1894 / 96$. 
Urbanizaciones cerradas en áreas inundables del municipio de Tigre: ¿producción de espacio urbano de alta calidad ambiental?

Figura 3. Mapa de Nordelta. Plan director de fines de los años ochenta

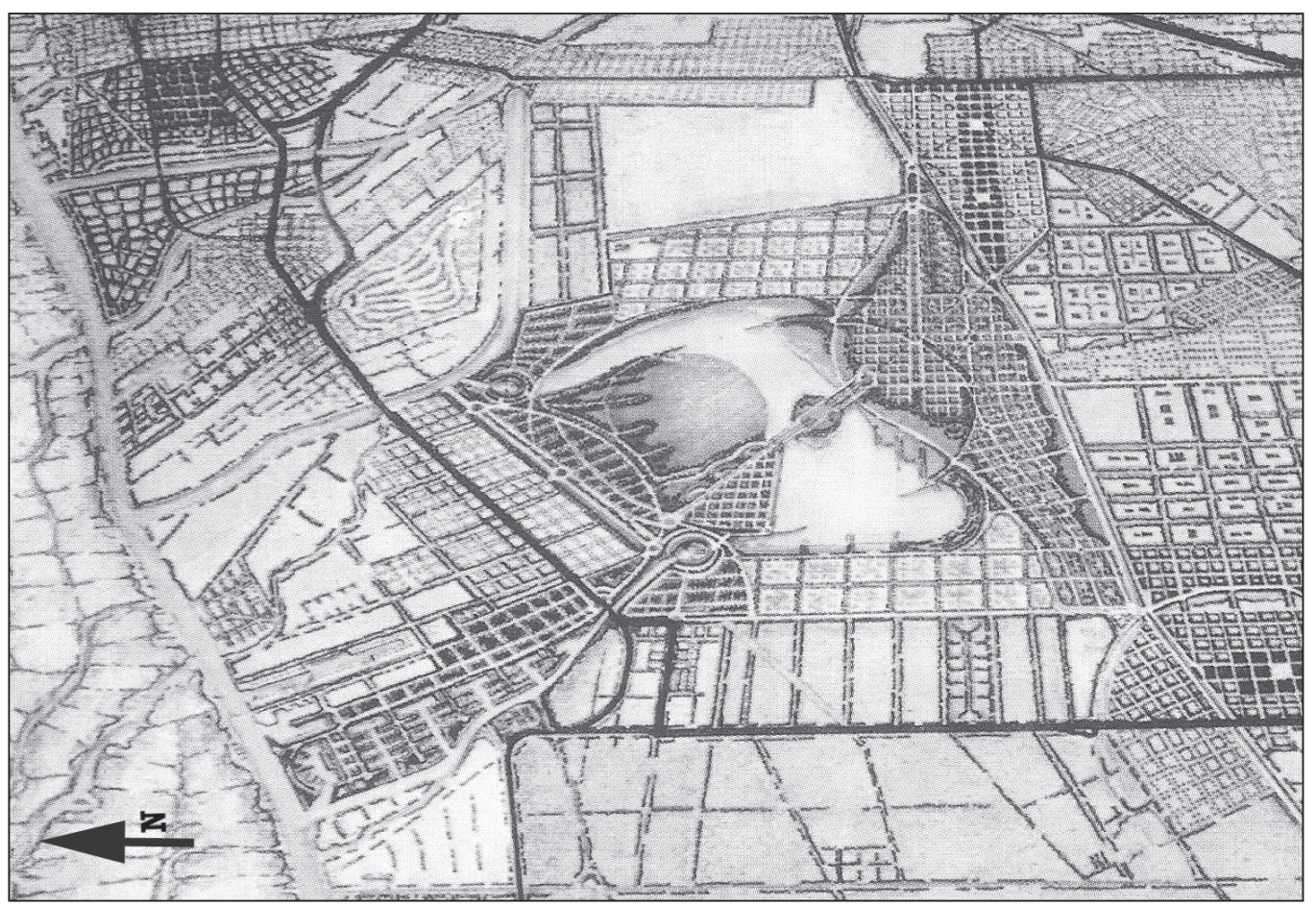

Fuente. Pesci (2003).

proyecto se advierte una supresión de las formas rectas y ortogonales que rememoran el espacio -sobre todo público- de la ciudad tradicional (De Terán, 1999), por un predominio de formas redondeadas, evidentes en el trazado de las calles, en la transformación del gran lago central (aumento del número de penínsulas, bahías e islas) y en la multiplicación de lagos menores. Dichos cambios implicaron una disminución de los espacios públicos del plan director inicial, tales como las veredas y las importantes áreas verdes contiguas al gran lago central, con el objeto de maximizar la comercialización de las superficies del emprendimiento (ver Figura 4). Estas transformaciones del espacio pueden entenderse ante el contexto de un nuevo mercado residencial (oferta de barrios cerrados y demanda de las nuevas clases media-altas) dentro del "imaginario verde" y el valor de la seguridad de los años noventa y, también, del perfil que adquiere el grupo empresarial con la incorporación de Consultatio SA.

Asimismo, el desarrollo de esta mega-UC acrecienta el número de calles, que, según lo contemplado en el decreto-ley 8912/77 sobre los nuevos núcleos urbanos, deberían ser de acceso público y de dominio municipal. A pesar de ello, la municipalidad de Tigre, a través del decreto $\mathrm{N}^{\circ}$ 714 del 2001, le cedió su uso a Nordelta hasta finalizar las obras. Esa cesión podría ser a muy largo plazo, si se considera que la duración del proyecto es de 20 años. Pero sobre todo por el papel que está llevando a cabo el gobierno municipal en la relación público-privada en las últimas décadas.

La propuesta del plan director de Nordelta se efectuó bajo la impronta de las nociones de "sustentabilidad ambiental" divulgadas desde las últimas décadas del siglo XX, y que el propio CEPA está difundiendo ${ }^{28}$. Por esa razón no solo se planificaron los aspectos meramente urbanísticos, sino que se formularon a través del plan director

28 Desde 1989 el CEPA dirige el "Foro Latinoamericano de Ciencias Ambientales" (FLACAM), desde el cual se realizan proyectos de sustentabilidad y se dicta la Maestría en Desarrollo Sustentable en asociación con la Universidad Nacional de Lanús. 
Figura 4. Mapa de Nordelta. Plan director de fines de los años noventa

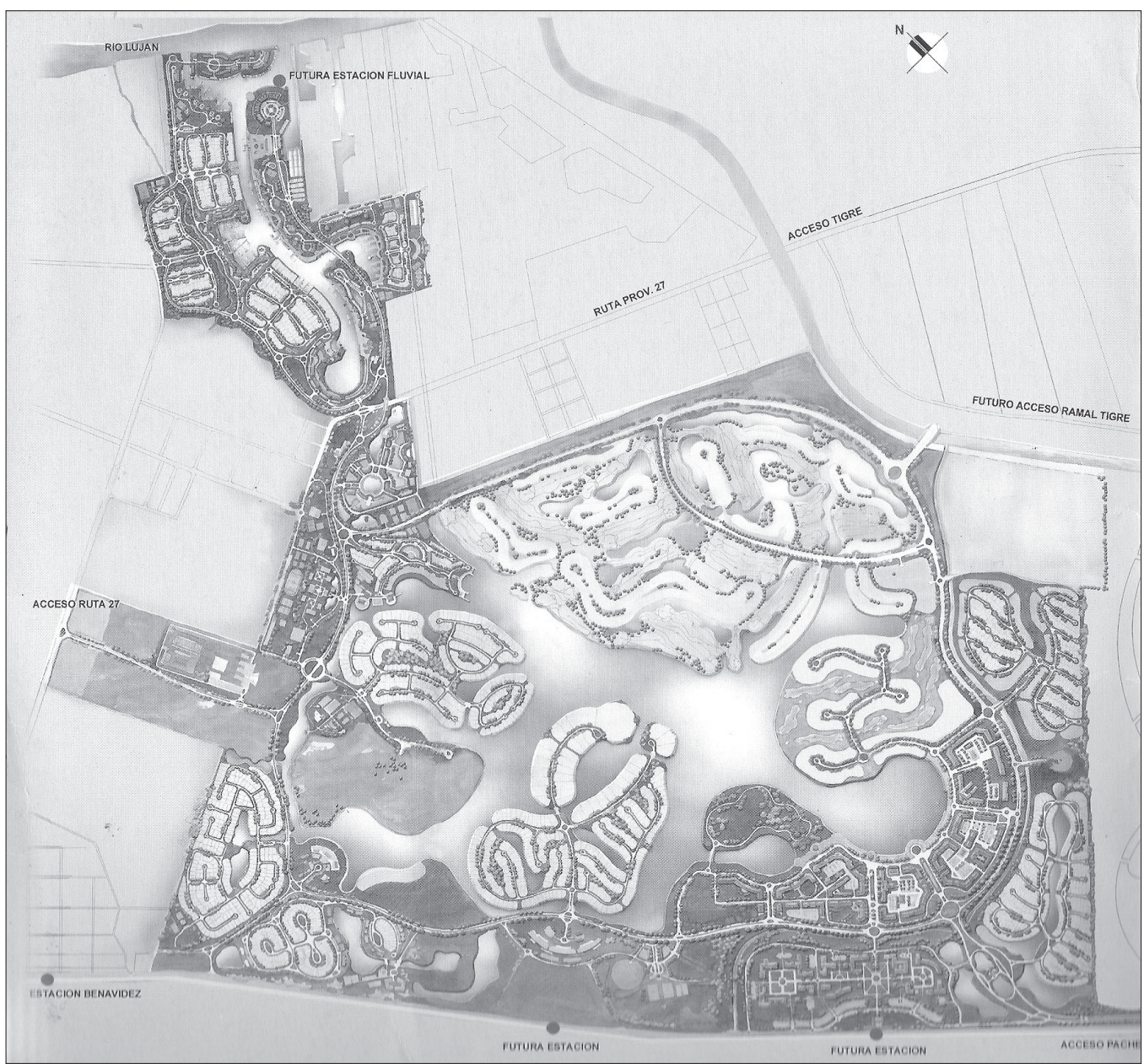

Fuente. Folletería comercial de Nordelta (s/f).

$y$, también, del plan de manejo ambiental integrado (efectuado este último por la consultora Estudio E3), un conjunto de recomendaciones $y$ medidas organizacionales y funcionales en torno a la temática ambiental, que comprende desde aspectos como la forestación con árboles autóctonos, la incorporación de prácticas eficientes de ingeniería ambiental hasta el manejo de desastres de inundaciones (Ríos, 2005). Estas características, entre otras, son las que permiten a Nordelta diferenciarse de otras UC como ciudad ambiental. Según la revista Ambiente, editada por el CEPA, Nordelta es un proyecto sustentable de características únicas:
- En "lo ecológico", porque posee $1600 \mathrm{ha}$. saneadas, según criterios hidrológicos y paisajísticos adecuados, 300 ha. están destinadas a parques y lagos de gran cuidado ecológico;

- En "lo socioeconómico", porque la población esperada de 140.000 habitantes brindaría amplias posibilidades de empleo y una oferta excepcional para inversiones privadas en residencias, centros comerciales, centros turísticos, oficinas, empresas, etc.; y

- En "lo socio-cultural”, porque ofrecerá una nueva centralidad urbana, que fortalecerá y equiparará la posibilidad de vivir y trabajar en un mejor paisaje. Contará con todos los 
servicios y la infraestructura básica completa que puede brindar una ciudad. Reforzará la identidad del Tigre y la valoración del Delta, etc. (Pérez, 1999).

Como se puede advertir, la sustentabilidad ambiental es uno de los fundamentos de ese discurso. Los planes directores juegan un papel protagónico en la legitimación de las UC como productos de "alta calidad ambiental", en donde parece que hasta el más mínimo detalle ha sido planificado por los actores económicos privados, de acuerdo a lo manifestado por el actual presidente de Nordelta en los medios gráficos (Sánchez, 2000): "La ciudad ha sido diseñada con el objetivo de buscar un balance entre los espacios verdes, el agua y las áreas urbanas [...] el medio ambiente provisto está caracterizado por su armonía urbana y estética y la diferente densidad de poblaciones, así como la distribución adecuada del tráfico” (p. 2).

Los desarrolladores e inversores sostienen que con el cumplimiento del plan director diseñado para la mega-UC se evitarán los problemas tradicionales de los centros urbanos: inseguridad, contaminación ambiental, paisajes deteriorados, etc. Expresiones como estas marcan la importancia que está alcanzando la planificación urbana privada a partir del desarrollo de las mega-UC en Argentina durante los años noventa, "superadora" supuestamente de los errores cometidos por parte de la planificación estatal en décadas anteriores. No deja de resultar paradójico que, sobre la base del debilitamiento de la planificación estatal, se haya fortalecido una rígida planificación privada, no ya con sentido público, sino para el aprovechamiento privado. Planificación estricta del emprendimiento privado, dentro de una ciudad con mínimas regulaciones y controles.

\section{Algunas consideraciones finales}

Actualmente, cerca del 25 por ciento de la superficie del AGBA pertenece a áreas inundables, siendo las cuencas de los ríos Matanza-Riachuelo, Reconquista, Luján y los bajos ribereños del Río de la Plata (como también el Delta del Paraná) áreas de expansión urbana, en las que participan no solo los históricos loteos populares (muchos de ellos ilegales) sino también, desde los años noventa, las UC construidas sobre rellenos (Clichevsky, 2002).

Como puede observarse, la planificación urbana está siendo apropiada por los actores económicos privados productores de UC (sobre todo para el caso de las mega-UC), no ya como un intento de orientación pública y búsqueda de objetivos generales, sino como manera de producir territorios que satisfagan necesidades privadas. Así, pedazos del AGBA se están produciendo como resultado de una fuerte planificación "interna" de todos los componentes, cuya finalidad es aumentar la calidad del producto inmobiliario y la rentabilidad (Pírez, 2004).

Las planificadas mega-UC se colocan como "nuevos productos verdes" dentro del mercado de consumo residencial, siendo los planes directores y los planes de manejo ambiental "nuevas etiquetas verdes" que certificarían la calidad de esos productos, medidos a través de indicadores ambientales, tales como: proporción de espacios verdes "públicos" sobre los destinados a viviendas y servicios, tipo de árboles, de céspedes en las canchas de golf, de peces implantados en los lagos (si son autóctonos, mejor aún).

En oposición a lo que sostiene el discurso de la "sustentabilidad ambiental", la expansión de las UC sobre rellenos en áreas inundables involucra impactos negativos de importantes magnitudes. Concretamente, esa "naturaleza" vendida en fragmentos, en pedazos, por estos emprendimientos inmobiliarios, ha sido transformada, alterando tanto su forma como sus funciones. Al simular los rellenos espacios no inundables, se niegan las cualidades físico-naturales propias que estos ecosistemas tienen. En este caso, los humedales pertenecientes al sector continental de Tigre se han transformado en "islotes de UC", participando en la desaparición de importantes "servicios" que brinda este ecosistema: regulación hidrológica, refugio de especies autóctonas, depuración de aguas, recarga y descarga de acuíferos, etc. (Canevari, Blanco y Bucher, 1999; Fernández, 2002; Daniele et al., 2006).

La alteración de esos servicios repercutirá en una probable (aunque todavía no estudiada en profundidad) potenciación de la peligrosidad (por 
lo menos a un nivel de micro-escala): las inundaciones recurrentes. Simultáneamente, el desarrollo de este negocio urbano conlleva a una creciente construcción de la vulnerabilidad social frente a los desastres. A pesar de que se hayan tomado medidas de mitigación como sistemas constructivos o estrategias de manejo de desastres de manera privada, los sectores que se incorporan a esas áreas no tienen la práctica de haber experimentado las inundaciones; es decir, no adquirieron el conocimiento, que sí conserva un porcentaje importante de las poblaciones históricas de los alrededores, de cómo manejarse, a quiénes recurrir, hacia dónde dirigirse, etc. en el momento de la emergencia que genera un desastre. En consecuencia, se considera que la construcción de UC sobre rellenos comprende nuevas formas de producción de riesgos de desastres en áreas inundables de la periferia del AGBA (Ríos, 2005).

A partir del escenario analizado se observa un pasaje de responsabilidades -de lo privado a lo público- en la atención de las "externalidades" (es decir, los desastres, los impactos por contaminación, etc.) derivadas de los cambios producidos por las UC y obras conexas. Así, mientras se sobrecarga el gasto público (atención de la emergencia, reconstrucción, rehabilitación, etc.) sobre todo en el nivel local (máximo responsable de la Defensa Civil municipal), la iniciativa privada solamente asume los beneficios de este proceso, por lo menos mientras no ocurra un desastre de grandes magnitudes que supere la cota de "seguridad" de los rellenos.

Los impactos negativos generados son evidencia de cómo los costos y los beneficios ambientales son desigualmente distribuidos en términos sociales. El análisis presentado pone de relieve cómo la lógica de la producción del espacio continúa efectuándose a expensas del deterioro socio-ambiental de los sectores con menor poder: los habitantes más antiguos pertenecientes a los sectores medios y bajos de esas áreas de Tigre.

Según los actores económicos privados, la construcción de UC sobre rellenos permite recuperar esas áreas bajas y ecológicamente deterioradas, sin las cuales los terrenos seguirían siendo baldíos y "peligrosos". Ese peligro no parece estar asociado a las características físico-naturales predominantes de esas áreas (las inundaciones recurrentes), sino a la posibilidad de que las mismas sean apropiadas por sectores populares, poniéndole un límite a la transformación de ese espacio inundable en el negocio urbano del "nuevo Tigre". En estos procesos se puede visualizar una disputa por la apropiación del espacio de la periferia inundable del AGBA entre los sectores que llevan a cabo y consumen las UC construidas sobre rellenos y los sectores populares que históricamente no tienen más opción que ocupar tierras desvalorizadas como son esos espacios inundables.

La necesidad de divulgar a las UC como "espacios verdes", de "vida saludable", lejos del contaminado centro metropolitano, enmascara la obtención de grandes lucros. En realidad, se comercializan tierras destinadas a la producción agrícola (de baja calidad) que luego son vendidas como tierras urbanas. Asimismo, la valorización de las cualidades "naturales" únicas de esos espacios (como las características del paisaje del Delta o de la costa de Río de la Plata), en un contexto de creciente sensibilidad ecológica, permite la obtención de lucros que se obtienen de una renta monopólica. Se suman de esta forma esos dos procesos para hacer a esas operaciones inmobiliarias altamente rentables.

Ahora bien, ¿̨qué otras cuestiones están por detrás de esa sustentabilidad ambiental en el caso del proyecto Nordelta y de las otras UC del estilo?

El discurso de "lo sustentable", difundido desde una retórica crecientemente hegemónica, que articula una coalición de intereses entre los actores económicos privados y los gobiernos locales, se instala como una suerte de "pensamiento único", a-político, por ende consensual. En realidad ha sido colocado por aquellos que tienen mayor capacidad (o poder) para legitimarse en el espacio social, para justificar sus acciones (Acselrad, 1999). En este caso, el discurso se apoya en proposiciones desarrolladas por el conocimiento científico-técnico (el "saber experto"). Es muy grande la cantidad de revistas, cursos de postgrado, congresos, etc., que desde distintas disciplinas del conocimiento (desde el urbanismo hasta la ecología) nutren y legitiman tal discurso. 
Urbanizaciones cerradas en áreas inundables del municipio de Tigre: ¿producción de espacio urbano de alta calidad ambiental?

Presentar a Nordelta como un proyecto "sustentable" en términos ecológicos, socioeconómicos o socioculturales implica esconder, ocultar el conflicto social intrínseco que se halla en el propio proceso de producción de ese espacio, naturalizando desde el enfoque discursivo esos procesos (Lefebvre, 1995; Carlos, 1994). Se opera una despolitización de las consecuencias que traen aparejadas esos enormes negocios urbanos, rechazando la existencia de conflictos sociales que tienen como base al ambiente, la economía y la producción del espacio. En suma, el discurso de "lo sustentable" disimula los problemas del espacio cada vez más desigual y de su producción.

Detrás de esa despolitización parece encontrarse una política urbana local particular. Es el gobierno municipal quien genera las condiciones para que esas grandes inversiones urbanas puedan realizarse: cambios en la regulación, gestiones o articulación de diferentes actores públicos y privados y oferta de financiamiento. Se observa, en consecuencia, una asociación entre las autoridades locales y los desarrolladores de las UC que se basa, por una parte, en la realización de los negocios urbanos y, por la otra, en la búsqueda de un modelo de municipio de clases medias. El gobierno municipal contribuye a legitimar la producción de UC garantizando condiciones de calidad asociadas con la exclusividad del producto. Esa asociación, que parece acercarse a lo que se ha llamado la “máquina del desarrollo urbano" (Molotch, 1976), tiene como resultado más inmediato la orientación de la producción inmobiliaria hacia los sectores medios y medios altos, sin atender las necesidades de vivienda e infraestructura de la población de ingresos medio-bajos y bajos del municipio. En definitiva, parece que se busca una redefinición socioeconómica del municipio, más homogéneamente basada en los sectores medios, más allá de los costos ambientales y sociales que acarrea. Todo ello en un proceso que aparece caracterizado por la articulación entre el discurso ambiental y la cooperación público-privada.

\section{Referencias bibliográficas}

Acselrad, H. (1999). Sustentabilidad y ciudad. EURE, 25, 74, 36-46.
Alphandéry, P., Bitoun, P. \& Dupont Y. (1992). O equivoco ecológico. Riscos políticos da inconseqüiencia. São Paulo: Brasiliense.

Astolfoni, J. \& Constantini E. (1999). ¿Por qué Nordelta? Ambiente. Ética y estética para el ambiente construido, 80, 10-11.

Blakely, E. \& Snyder M. (1997). Fortress america: gated communities in the United States. Washington D.C.: Brookings Institution PressLincoln Institute of Land Policy.

Caldeira, T. P. R. (2000). City of walls: crime, segregation, and citizenship in São Paulo. Berkeley: University of California Press.

Canevari, P., Blanco, D. \& Bucher E. (1999). Los beneficios de los humedales de la Argentina. Amenazas y propuestas de soluciones. Buenos Aires: Wetlands International.

Carlos, A. F. (1994). O meio ambiente urbano e o discurso ecológico. Revista do Departamento de Geografia/USP, 8, 75-78. (2004). O espaço urbano. Novos escritos sobre a cidade. São Paulo: Contexto.

Clichevsky, N. (2002). Pobreza y politicas urbanoambientales en Argentina. Santiago de Chile: CEPAL- ECLAC, División de Medio Ambiente y Asentamientos Humanos.

Daniele, C., Ríos, D., De Paula, M. \& Frassetto, A. (2006). Impacto y riesgo de la expansión urbana sobre valles de inundación en la Región Metropolitana de Buenos Aires. En A. Brown et al. (Ed.), Situación ambiental Argentina 2005 (1a.ed., pp. 457-461). Buenos Aires: Fundación Vida Silvestre Argentina.

Davis, M. (1990). City of quartz. Excavating the future in Los Angeles. New York: Vintage.

De Terán, F. (1999). La ciudad dialéctica. Ambiente. Ética y estética para el ambiente construido, segunda época, 80, 28.

Fernández, K. \& Gutiérrez Brito, J. (1997). Consumo y medio ambiente. En J. Ballesteros \& J. Pérez Adán (Ed.), Sociedad y medio ambiente (1a.ed., pp. 83-102). Madrid: Trotta.

Fernández, L. (2002). Los servicios ecológicos que cumplen los humedales. El caso de Tigre, Buenos Aires, Tesis de licenciatura en Ecología Urbana, Universidad Nacional de General Sarmiento, Los Polvorines, provincia de Buenos Aires, Argentina. Recuperado el 25 de julio de 2005, de http://www.urbared.ungs.edu.ar/textos/tesis_ecolog\%EDa.pdf. 
Fishman, R. (1987). Bourgeois utopias. The rise and fall of suburbia. New York: Basic Books.

Gaviria, M. (1971). Campo, urbe y espacio del ocio. Madrid: Siglo XXI de España Editores.

Girola, M. (2005). Procesos de recualificación urbana desde una perspectiva comparativa: análisis de casos en la centralidad y la periferia del Área Metropolitana de Buenos Aires. En Terceras Jornadas de Investigación en Antropología Social, SEANSO- ICA- FFyL (pp. 887897), Buenos Aires: Universidad de Buenos Aires (publicación en CD).

Glasze, G. (2005). Some reflections on the economic and political organisation of private neighbourhoods. Housing Studies, 20, 2, 221-233.

Harvey, D. (2005). A produção capitalista do espaço. São Paulo: Annablume.

Herzer H. \& Clichevsky, N. (2001). Perspectiva histórica: las inundaciones en Buenos Aires. En A. Kreimer et al. (Ed.), Inundaciones en el Área Metropolitana de Buenos Aires (1 ${ }^{\mathrm{a}}$.ed., pp.33-45). Washington D.C.: World Bank, Disaster Management Facility.

INDEC. (2001). Censo nacional de población, hogares y vivienda. Buenos Aires: Autor. (2003). ¿Qué es el Gran Buenos Aires? Buenos Aires: Autor.

Janoschka, M. (2002). El nuevo modelo de ciudad latinoamericana: fragmentación y privatización. EURE, 28, 85, 11-20.

Lanusse, G. (2005). Entrevista al intendente de Tigre Sr. Ricardo Ubieto. Cara a cara con Ubieto. Recuperado el 26 de junio de 2006, de: http://www.eidico.com.ar/eidico/index/ $\mathrm{VN}$-ubieto.pdf.

Lefebvre, H. (1976). Espacio y politica. Barcelona: Ediciones Península.

(1995). The production of space. Oxford (UK)/Cambridge (USA): Blackwell Publishers.

Lindón, A. (1989). Ciudad de Buenos Aires: producción de espacio urbano en sitios vulnerables a inundación entre 1580-1880. Tesis de Licenciatura en Geografía no publicada, Universidad de Buenos Aires, Buenos Aires, Argentina.

Lipovetsky, G. (1996). El crepúsculo del deber. La ética indolora de los nuevos tiempos democráticos. Barcelona: Anagrama.
Martínez-Echevarría y Ortega, M. (1997). La empresa como problema ecológico. En J. Ballesteros \& Pérez Adán, J. (Ed.), Sociedady medio ambiente (1ª.ed., pp. 103-128). Madrid: Trotta.

Molotch, H. (1976). The city as a growth machine: Towards a political economy of place, American Journal of Sociology, 82, 2, 309-332.

Moraes, A. \& Da Costa, W. (1987). Geografía crítica. A valorização do espaço. São Paulo: Editora HUCITEC.

Municipalidad de Tigre (2006). Digesto. Recuperado el 18 de mayo de 2006, de: http://www. tigre.gov.ar/mainsite/mu-dig-inst.html.

Núñez T., Jankilevich, S., Brunstein, F. \& Pelfini, A. (1998). Agentes públicos y privados en la construcción de un desarrollo sustentable. Tigre: las dos caras de la ciudad global. Documento de trabajo. Buenos Aires: Universidad de Belgrano.

Pérez, J. (1999). El plan director. Antecedentes para una ciudad ambiental. Ambiente. Ética y estética para el ambiente construido, segunda época, 80, 15-19.

Pesci, R. (2003). Siete ciudades siete. Luces y sombras de 7 ciudades en búsqueda de la sustentabilidad [versión electrónica]. Ambiente. Ética y estética para el ambiente construido, 91. Recuperado el 5 de junio de 2006, de: http:// www.revista-ambiente.com.ar/ultimos_numeros/n91.htm

Pírez, P. (2002). Buenos Aires: fragmentation and privatization of the metropolitan city. Environment and Urbanization, 14, 1, 58-76.

(2004). La configuración metropolitana de Buenos Aires: expansión, privatización y fragmentación. Realidad Económica, 208, 111-134.

Ríos, D. (2002). Vulnerabilidad, urbanizaciones cerradas e inundaciones en el partido de Tigre, durante el periodo 1990-2001. Tesis de Licenciatura en Geografía no publicada, Universidad de Buenos Aires, Buenos Aires, Argentina.

(2005). Planificación urbana privada y desastres de inundación. Las urbanizaciones cerradas polderizadas en el Municipio de Tigre, Buenos Aires. Revista Economía, Sociedad y Territorio, 5, 17, 63-83. 
Urbanizaciones cerradas en áreas inundables del municipio de Tigre: ¿producción de espacio urbano de alta calidad ambiental?

Sánchez, L. (2000). La llegada del aluvión edilicio. Diario Página 12, 11/11/2000: 2.

Santana, P. de (1999). A mercadoria verde: a natureza. En A. Damiani et al. (Org.) O espaço no fim de sêculo. A nova raridade (1a.ed., pp. 91- 109). São Paulo: Contexto.

Suárez, F. \& Lombardo, R. (2004). Pitting the pulluted against the flooded: water resource management Tigre, Buenos Aires. Environment and urbanization, 16, 2, 185-198.

Thomas, T. (1994). A ecologia do absurdo. Lisboa: Edições Dinossauro.

Torres, H. (2001). Cambios socioterritoriales en Buenos Aires durante la década de 1990. EURE, 27, 80, 33-56.
Vidal Koppmann, S. (2002). Nuevas fronteras intraurbanas: de los barrios cerrados a los pueblos privados. Buenos Aires, Argentina. En F., Cabrales Barajas (Comp.), Latinoamérica: países abiertos, ciudades cerradas ( $1^{\mathrm{a}}$.ed., pp. 261-286). Guadalajara: Universidad de Guadalajara- UNESCO.

Videla, E. (2002). Vecinos del Delta en pie de guerra contra un puente hacia las islas. Diario Página 12. Recuperado el 29 de abril de 2006, de: http://www.pagina12.com.ar/diario/socie$\mathrm{dad} / 3-3457-2002-04-01 . h t m l$ 